\title{
Autophagy Promotes Oligodendrocyte Survival and Function following Dysmyelination in a Long-Lived Myelin Mutant
}

\author{
Chelsey M. Smith, Joshua A. Mayer, and Ian D. Duncan \\ University of Wisconsin-Madison, School of Veterinary Medicine, Madison, Wisconsin 53706
}

The Long-Evans shaker (les) rat has a mutation in myelin basic protein that results in severe CNS dysmyelination and subsequent demyelination during development. During this time, les oligodendrocytes accumulate cytoplasmic vesicles, including lysosomes and membrane-bound organelles. However, the mechanism and functional relevance behind these oligodendrocyte abnormalities in les have not been investigated. Using high-magnification electron microscopy, we identified the accumulations in les oligodendrocytes as early and late autophagosomes. Additionally, immunohistochemistry and Western blots showed an increase in autophagy markers in les. However, autophagy did not precede the death of les oligodendrocytes. Instead, upregulating autophagy promoted membrane extensions in les oligodendrocytes in vitro. Furthermore, upregulating autophagy in les rats via intermittent fasting increased the proportion of myelinated axons as well as myelin sheath thickness in les and control rats. Overall, this study provides insight into the abnormalities described in les as well as identifying a novel mechanism that promotes the survival and function of oligodendrocytes.

\section{Introduction}

The myelin sheath is essential for the rapid conduction velocity of the nerve fiber via saltatory conduction (Yin et al., 2006) and can aid in maintaining axonal integrity (Griffiths et al., 1998; Bjartmar et al., 1999; Scherer, 1999; Nave and Trapp, 2008; Soldan and Pirko, 2012). Animal models with mutations in myelin genes have been essential for elucidating the role of several proteins that are critical for myelin development and maintenance (Campagnoni and Skoff, 2001). One such mutant, the Long-Evans shaker (les) rat, has an abnormal insertion in the gene that encodes myelin basic protein (MBP). This mutation disrupts the splicing and subsequent translation of functional MBP (O'Connor et al., 1999). MBP is an important structural component of the myelin sheath that is necessary for the formation of the major dense line in compact myelin. More recently, $\mathrm{MBP}$ has also been shown to play a role in the transport and assembly of myelin sheath lipids and proteins (Harauz et al., 2004; Fitzner et al., 2006; Simons and Trotter, 2007).

At peak myelin development (2 weeks), les mutants develop thin, uncompact myelin. Most of this myelin is lost by 4 weeks,

\footnotetext{
Received Jan. 17, 2013; revised Feb. 28, 2013; accepted March 26, 2013.

Author contributions: C.M.S., J.A.M., and I.D.D. designed research; C.M.S. performed research; C.M.S. analyzed data; C.M.S. and I.D.D. wrote the paper.

This work was supported by a National Science Foundation Graduate Research Fellowship, the University of Wisconsin Neuroscience Training Program (Training Grant T32-GM007507), the University of Wisconsin Graduate Women in Science, the University of Wisconsin Graduate School Fall Competition award, and the Oscar Rennebohm Foundation. We thank Dr. John Svaren and Dr. Troy Hornberger for their thoughtful review of this manuscript, Loklan Sherrington for assistance with tissue processing and electron microscopy, and Sarah Martin for assistance with animal care.

The authors declare no competing financial interests.

Correspondence should be addressed to Dr. Ian D. Duncan, University of Wisconsin-Madison, School of Veterinary Medicine, 2015 Linden Drive, Madison, WI 53706. E-mail: duncani@svm.vetmed.wisc.edu.

DOI:10.1523/JNEUROSCI.0233-13.2013

Copyright $\odot 2013$ the authors $\quad 0270-6474 / 13 / 338088-13 \$ 15.00 / 0$
}

and by 8 weeks little myelin is present within the CNS of les rats (Delaney et al., 1995; Smith et al., 2013). Moreover, during this time of myelin development and loss, affected oligodendrocytes develop an abnormal morphology. Beginning at 2 weeks, mutant oligodendrocytes progressively accumulate vesicles, lysosomes, and membrane-bound organelles. As the animal ages, les oligodendrocytes contain fewer abnormal inclusions yet lack normal Golgi apparatus and endoplasmic reticulum (ER) (Kwiecien et al., 1998). The mechanism behind and the relevance of these accumulations have yet to be determined and may provide insight as to why les oligodendrocytes are unable to maintain myelin beyond the early stages of development.

The transient accumulation of vesicles and membrane-bound organelles suggests that les oligodendrocytes are undergoing a selfdigestive pathway known as macroautophagy (hereafter referred to as autophagy). Autophagy is a major cellular degradation pathway that is capable of digesting cytoplasmic components through an autophagosome-lysosome system (Klionsky and Emr, 2000). The abnormal accumulations reported in les may indicate that les oligodendrocytes are undergoing increased levels of autophagy. To determine whether the abnormal oligodendrocyte morphology was the result of an upregulation of autophagy, we investigated whether les oligodendrocytes have an increase in several autophagy markers. Electron microscopy, immunohistochemistry, and Western blots demonstrated that les animals have increased levels of autophagy during dysmyelination and demyelination. However, autophagy did not correlate with an increase in oligodendrocyte death in les. Instead, upregulating autophagy in les oligodendrocytes in vitro increased the number of cells forming membrane extensions. Furthermore, by upregulating autophagy in vivo by intermittent fasting, both les and control animals had an increase in the number of myelinated axons as well as an increase in myelin sheath thickness. Therefore, we provide evidence that autophagy can play a novel role 
in oligodendrocyte survival and myelin development that may have broader implications for therapies to treat myelin disease.

\section{Materials and Methods}

Experimental animals. Animals were maintained at the School of Veterinary Medicine in compliance with the animal care committee at the University of Wisconsin-Madison. The les rats and normal littermates of either sex were collected at 1,2,3,4, and 6 weeks of age as well as 3, 6, and 9 months of age. Affected rats were identified by whole-body tremors at 12-14 d. Neonatal mutant and control rats were identified by presence or absence of the mutated MBP DNA sequence by PCR as previously described (O'Connor et al., 1999). Animals were housed in identical conditions, except with a few modifications found to enhance the survival of les mutants. Upon weaning at $28 \mathrm{~d}$, les rats were given individual blocks of phenobarbital-containing diet (1468.7 g ground rodent diet, Harlan; 97.1 g powdered milk, $97.1 \mathrm{~g}$ sugar, and $4.2 \mathrm{~g}$ powdered phenobarbitol solidified with gelatin and $1.75 \mathrm{~L} \mathrm{H}_{2} \mathrm{O}$ ) on the floor of their cage three times weekly. Phenobarbital was incorporated into the diet to reduce the severity of the tremor and seizures that are a result of the les phenotype. In addition, the les rats were given apple slices on the floor of the cage to ensure sufficient hydration and caloric intake.

Tissue embedding and processing. Control and les animals were deeply anesthetized with isoflurane followed by intracardiac perfusion with $0.01 \mathrm{~m}$ PBS (pH 7.4). After buffer clearance, the perfusion was performed using weak and strong Karnovsky's fixative. For resin embedding, thoracic spinal cords were postfixed in $1 \%$ osmium tetroxide $\left(\mathrm{OsO}_{4}\right)$ buffered in $1 \%$ potassium ferrocyanide. After the osmium postfixation, tissue blocks were incubated for $30 \mathrm{~min}$ in $1 \%$ aqueous uranyl acetate to enhance autophagosome membranes (Yla-Anttila et al., 2009) followed by dehydration in a series of increasing ethanol concentrations. Propylene oxide was used as a transitional fluid mixed 1:1 with resin overnight. The following day, tissue was incubated in pure resin for a $2 \mathrm{~h}$ infiltration period and polymerized at $60^{\circ} \mathrm{C}$ overnight. Thin sections $(1 \mu \mathrm{m})$ were cut and stained with toluidine blue (1 g toluidine blue and $1 \mathrm{~g}$ sodium borate in $100 \mathrm{ml}$ distilled $\mathrm{H}_{2} \mathrm{O}$ ). Ultrathin sections $(10 \mathrm{~nm}$ ) for electron microscopy (EM) were cut and stained with $2 \%$ uranyl acetate followed by lead citrate. Images were captured on a Hitachi H-7000 transmission electron microscope housed at the Wisconsin Veterinary Diagnostic Laboratory.

Western blot. After PBS perfusion, thoracic spinal cord tissues were collected from les and control rats $(n=3$ for each time point) and immediately flash frozen in liquid nitrogen. Protein was extracted using radioimmunoprecipitation assay buffer: $20 \mathrm{~mm}$ Tris, $150 \mathrm{~mm} \mathrm{NaCl}, 0.1 \%$ SDS, $1 \%$ NP40, and protease inhibitor (Complete, Roche) and quantified using the Quant-iT protein detection kit with the Qubit flourometer according to manufacturer's protocols (Invitrogen). A total of $20 \mu \mathrm{g}$ of each sample was run on a $12 \%$ acrylamide gel and blotted onto Immobilon-P membranes (Millipore) using the Mini-PROTEAN electrophoresis system (Bio-Rad). After immunoblotting, membranes were blocked for $1 \mathrm{~h}$ in $5 \%$ BSA in $20 \mathrm{~mm}$ Tris- $\mathrm{HCl}$ buffer $(150 \mathrm{~mm} \mathrm{HCl}$ and $0.05 \%$ Tween 20, pH 7.6). Membranes were incubated with the following antibodies overnight: rabbit anti-LC3B (1:1000; Cell Signaling Technology) or rabbit anti-p62 (1:10,000, Enzo Life Sciences). The membranes were reprobed with mouse anti- $\beta$-actin (1:20,000; Sigma) to ensure loading consistency. The integrated density of each band was measured using ImageJ software. Integrated densities were normalized to $\beta$-actin, and these values are expressed as relative integrated densities averaged for three animals per time point.

Immunohistochemistry. Control and les animals $(n=3$ for each time point) were perfused with PBS followed by $4 \%$ PFA. The spinal cords were dissected and postfixed overnight in $4 \%$ PFA. The tissue was cryoprotected in $15 \%$ sucrose, and $20 \mu \mathrm{m}$ sections were cut on a cryostat for free-floating immunohistochemistry. The free-floating sections were washed in $0.01 \mathrm{M}$ PBS plus $0.01 \%$ Tween and incubated overnight in the following primary antibodies: LC3B (1:500; Cell Signaling Technology), p62 (1:10,000; Enzo Life Sciences), proteolipid protein (PLP, 1:100,000; a gift from the laboratory of Dr. Ian Griffiths, University of Glasgow, Glasgow), glutathione-S transferase $\pi$ (GST- $\pi$, 1:30,000; Molecular Biology Laboratories), or anti-activated caspase-3 (1:1000; Millipore Bioscience
Research Reagents). Double labeling was performed by incubating each antibody separately overnight in $0.01 \mathrm{~m}$ PBS plus $0.01 \%$ Tween. The following day, sections were washed and incubated in a mixture of appropriate secondary antibodies. After overnight incubation in GST- $\pi$, tissue sections were slide-mounted and TUNEL was performed according to the manufacturer's instructions (Promega). A secondary antibody mixture against both GST- $\pi$ (anti-rabbit AlexaFluor-564, Invitrogen) and TUNEL (anti-strepavidin AlexaFluor-488) was used to visualize expression. Images were taken on a fluorescent microscope (Nikon E8000). Total cell counts were performed on five thoracic spinal cord tissues per animal ( $n=3$ for control and les) based on staining threshold and size using ImageJ software.

$\mathrm{O}^{+}$magnetic cell sort. Control and les spinal cords were dissected from 3 -week-old animals ( $n=3$ for control and les animals) in chilled buffer. Each spinal cord was washed in PBS and incubated with activated papain (Worthington) for $10 \mathrm{~min}$. Spinal cords were then dissociated in a succession of smaller bore fire-polished Pasteur pipettes. O4 (1:100) antibody (produced by mouse hybridoma cells in our laboratory) was used as a marker for mature oligodendrocytes and incubated with the dissociated tissue for $30 \mathrm{~min}$ on ice with agitation. After incubation with the primary antibody, rat anti-mouse IgM beads (Miltenyi Biotec) were added to the dissociated cells for $20 \mathrm{~min}$ on ice. Cells were each run through an LS separating column (Miltenyi Biotec) on a high magnetic field stand to collect cells for immunolabeling. Columns were removed from the stand, and the $\mathrm{O}^{+}{ }^{+}$-positive cells were collected in separate tubes. Immunolabeling was performed on a sample of plated cells to determine the efficacy of the sort. Protein was extracted from the samples with RIPA buffer and blotted as described above.

BrdU labeling. Control and les animals were injected intraperitoneally at $14 \mathrm{~d}$ with $50 \mathrm{mg} / \mathrm{kg} \mathrm{BrdU}$ (Sigma) dissolved in sterile PBS. BrdU injections were given every $8 \mathrm{~h}$ for a total of 6 injections over $2 \mathrm{~d}(14-15$ d) to label a sufficient number of cells. At $17 \mathrm{~d}$, half of the rats $(n=3$ for control and les) were perfused with $4 \%$ PFA and processed for double immunohistochemistry. The remaining rats $(n=3$ for control and les) were raised until 3 months when they were perfused with $4 \%$ PFA. Double immunohistochemistry was performed with a mouse anti-rat BrdU antibody (1:1000; Novus Biologicals) and GST- $\pi(1: 30,000)$ as described above. Before incubation in the primary antibodies, the tissue sections were incubated for $30 \mathrm{~min}$ in $\mathrm{HCl}$ to unmask the antigen signal for BrdU. The quantification of BrdU and GST- $\pi$-positive cells was performed using ImageJ software. The proportion of BrdU-positive oligodendrocytes was quantified for each animal $(n=3$ control and les for each time point) in the white matter of thoracic spinal cord and averaged across time points.

Oligodendrocyte cultures. Oligospheres were generated as previously described (Avellana-Adalid et al., 1996; Zhang et al., 1998; Larsen et al., 2008) from les and control littermates. Striata were dissected from neonatal rats (p4-p6) and centrifuged in ice-cold HBSS (Invitrogen). Cells were then resuspended in oligosphere media (70\% Neurosphere media, $30 \%$ B104 conditioned medium) (Larsen et al., 2008) and mechanically dissociated with a series of fire-polished Pasteur pipettes. Cells were divided equally among sterile $25 \mathrm{~cm}^{2}$ flasks and placed in a humidified $37^{\circ} \mathrm{C}, 5 \% \mathrm{CO}_{2}$ incubator. After maintaining cells for $\sim 4$ weeks to generate cultures that are primarily oligodendrocytes, oligospheres were dissociated and plated onto poly-L-ornithine-coated coverslips in glial differentiation media (GDM) (10 ml DMEM/F12, $500 \mu \mathrm{l} \mathrm{N1}, 100 \mu \mathrm{l} 10$ $\mu \mathrm{g} / \mathrm{ml}$ biotin, $300 \mu \mathrm{l} 20 \mu \mathrm{g} / \mathrm{ml} \mathrm{T3}, 500 \mu \mathrm{l} \mathrm{FBS}, 50 \mu \mathrm{l}$ insulin, $88.55 \mathrm{ml}$ sterile $\mathrm{H}_{2} \mathrm{O}$ ). Autophagy was induced with serum and glucose starvation by incubating cells for $48 \mathrm{~h}$ in Earle's Balanced Salt Solution (EBSS) (Invitrogen) with the addition of the above concentrations of N1, biotin, T3, and insulin. Mature oligodendrocytes were labeled for surface marker O1 (antibody produced by mouse hybridoma cells in our laboratory). To block autophagosome breakdown, chloroquine (CQ), was added to culture media at $30 \mu \mathrm{g} / \mathrm{ml}$ (Mizushima et al., 2010). Western blots were performed on protein isolated from les and control oligodendrocyte cultures with RIPA buffer and blotted using the same method as described above. Experiments were repeated in triplicates to ensure the accuracy of results. The results are reported as the average with SE across three separate experiments. 

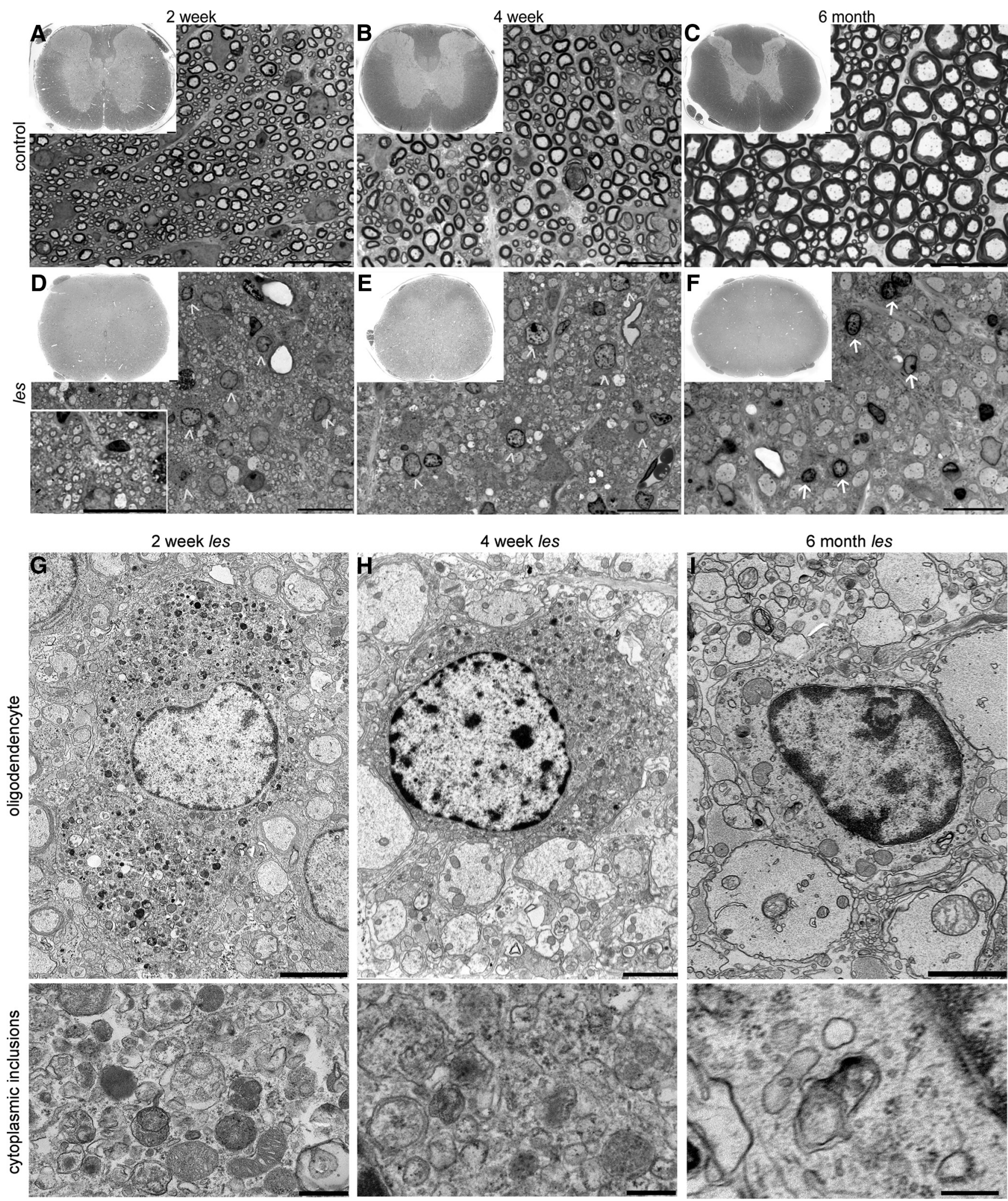

Figure 1. Representative images of toluidine blue-stained $1 \mu \mathrm{m}$ sections of control $(\boldsymbol{A}-\boldsymbol{C})$ and les $(\boldsymbol{D}-\boldsymbol{F})$ spinal cord. At 2 weeks, les axons develop thin myelin $(\boldsymbol{D}$, inset). However, most of this myelin is lost by 4 weeks $(\boldsymbol{E})$, and at later ages myelin is rare in the spinal cord of /es rats $(\boldsymbol{F})$. During myelin development and loss, les oligodendrocytes develop accumulations within their cytoplasm $(\boldsymbol{D}, \boldsymbol{E}$, arrowhead). At older time points, these cells continue to appear very abnormal $(\boldsymbol{F}$, arrow). Whole spinal cord images were taken with a $4 \times 0$ objective. The magnified inset at 2 weeks was taken with a $60 \times$ objective. Scale bars, $1 \mathrm{~mm}$. Electron micrographs of les oligodendrocytes through myelin development and loss $(\mathbf{G}-\mathbf{I})$. At 2 and 4 weeks, les oligodendrocytes are filled with abnormal inclusions, including vesicles, lysosomes, and membrane-bound organelles (G,H, enlarged image). At 6 months, les oligodendrocytes have fewer abnormal inclusions, lack normal Golgi and ER, and have a watery appearance to their cytoplasm (I, enlarged image). Images were taken at $2500 \times$ and $5000 \times$. Scale bars: $2500 \times, 2 \mu \mathrm{m} ; 5000 \times, 500 \mathrm{~nm}$. 

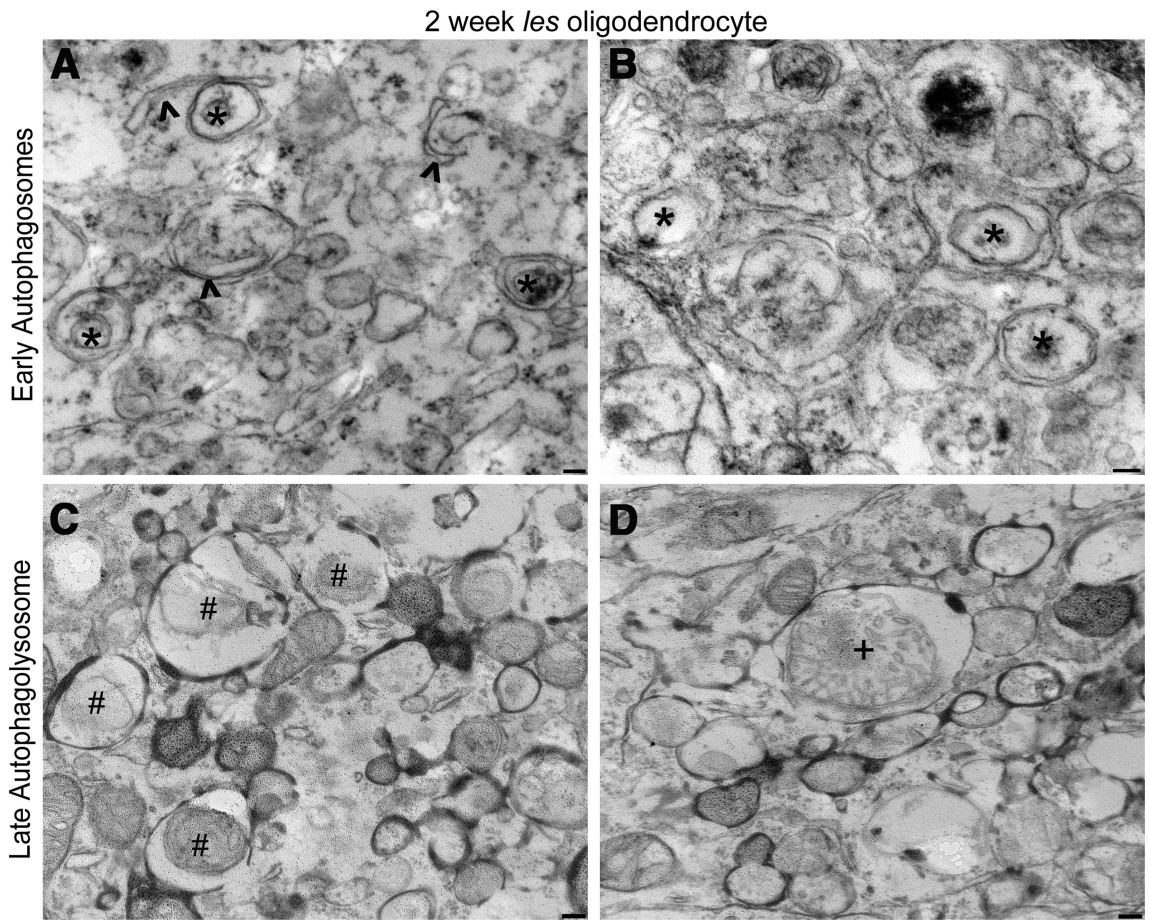

Figure 2. Representative electron micrographs of inclusions within 2-week-old oligodendrocytes in les spinal cord. There is clear evidence of inclusion membranes $(\boldsymbol{A}, \wedge)$ and early autophagosomes in les oligodendrocytes $\left(\boldsymbol{A}, \boldsymbol{B},{ }^{*}\right)$. In addition, late autophagolysosomes $(\boldsymbol{C}, \#)$ and mitochondria being degraded $(\boldsymbol{D},+)$ are also present within the cytoplasm of les oligodendrocytes. Original magnification, $\times 5000$. Scale bars, $100 \mathrm{~nm}$.
Intermittent fasting. At 4 weeks of age, control and les rats were randomly divided into four groups based on diet: control AL, control IF, les AL, or les IF. Control and les rats in the AL group were given ad libitum access to food. Rats in the IF group were given food every other day (at $\sim 8: 00$ AM everyday, food was given or taken away) as previously described (Madorsky et al., 2009). IF or AL was continued for 2 months until the rats reached 3 months of age. At this point, animals were killed and tissue was collected for each assay as described above.

Statistical analysis and image processing. For each time point, $n \geq 3$ for control and mutant rats were collected. Two-tailed Student's $t$ tests were performed on data comparing control and affected animals at the same time point unless otherwise stated. $p$ values $<0.05$ were deemed significant. All statistical analysis was performed with Excel or Prism software. All images were processed in Photoshop software. The image levels were adjusted to enhance clarity, the images were cropped for figures, and the focus was unmasked to sharpen each image.

\section{Results}

Myelin loss coincides with abnormal oligodendrocyte morphology

During peak myelin development at 2 weeks, les rats developed thin, uncompact myelin sheaths. However, most of this
A

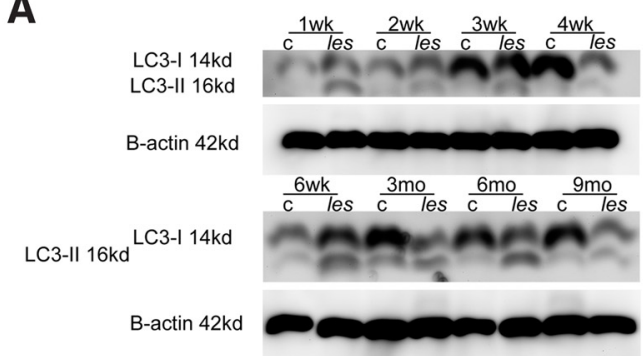

B

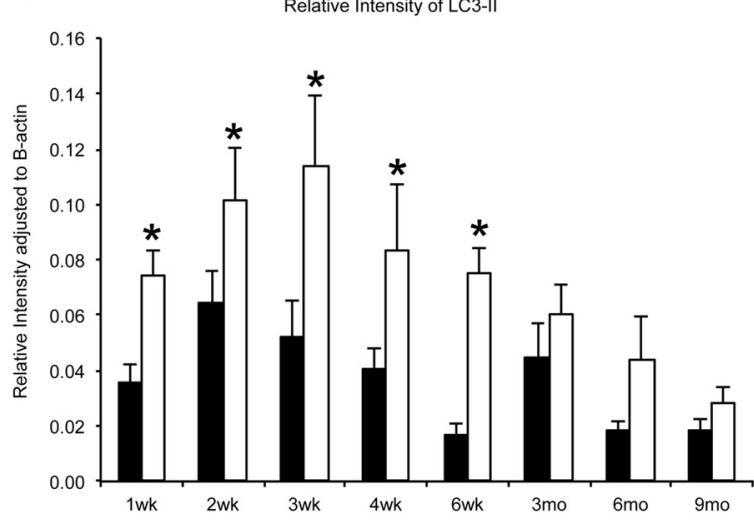

C
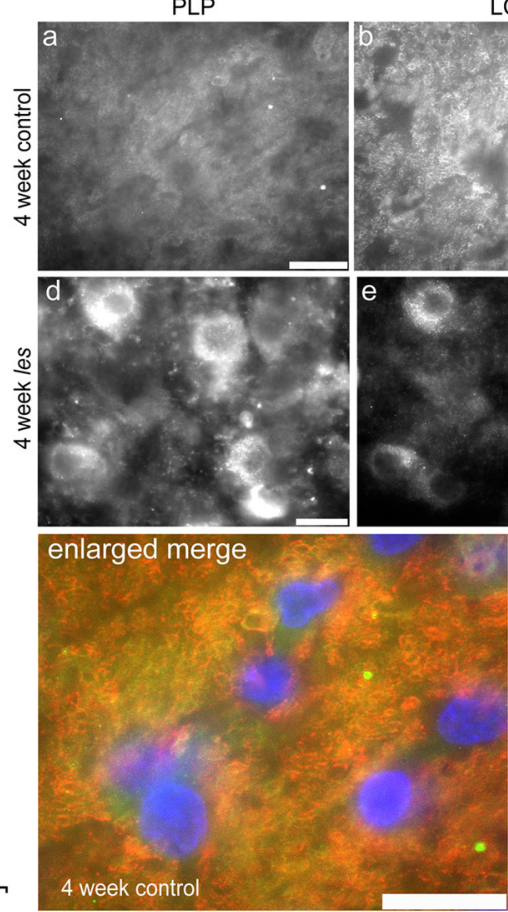

LC3
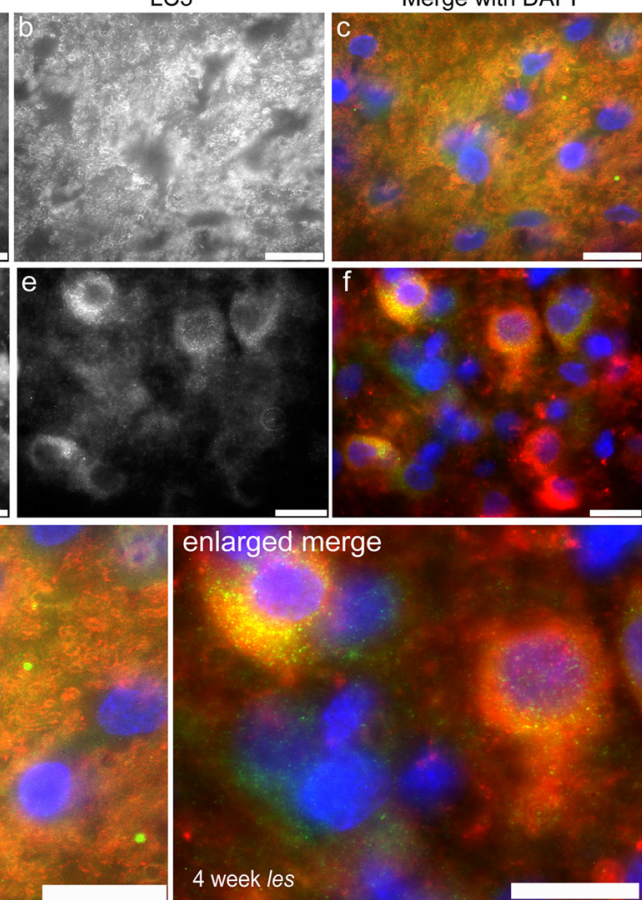

Figure 3. Expression of LC3 in les and control spinal cord tissue throughout development. Western blot of whole spinal cord homogenates show that LC3-II is expressed significantly higher in les spinal cord homogenates $(A) .{ }^{*} p<0.05$. Quantification of the Western blots shows that LC3-II expression peaks between 2 and 4 weeks when vesicles were observed within les oligodendrocytes (B). Representative images of immunohistochemical labeling for LC3 (green), PLP (red), and DAPI (blue) ( $\boldsymbol{C}$ in control ( $\boldsymbol{C} \boldsymbol{a}-\boldsymbol{c})$ and les ( $\boldsymbol{C} \boldsymbol{d}-\boldsymbol{f})$ spinal cord sections. In control rats, LC 3 is expressed diffusely throughout the cytoplasm of oligodendrocytes ( $\boldsymbol{a}-\boldsymbol{c}$, enlarged merge). However, LC3 is expressed as punctate bodies in PLP aggregates within les oligodendrocytes ( $\boldsymbol{d}-\boldsymbol{f}$, enlarged merge). Images were taken with an $100 \times$ objective. Scale bars, $1 \mu \mathrm{m}$. 
myelin was lost by 4 weeks, and by 3 months myelin sheaths were rare in the spinal cord of les rats (Fig. 1). During this membrane development and loss between 2 and 4 weeks, there was an abundance of oligodendrocytes in les spinal cord that were filled with abnormal inclusions (Fig. $1 D, E$, arrowheads). The cytoplasm of les oligodendrocytes became progressively filled with vesicles, lysosomes, and membrane-bound organelles (Fig. $1 G, H$, enlarged image). Between 3 and 9 months, the majority of les oligodendrocytes still appeared abnormal (Fig. $1 F$, arrows). Although the density of inclusions decreased, les oligodendrocytes had a watery appearance to their cytoplasm and lacked normal ER and Golgi (Fig. 1I, enlarged image).

\section{There is an increase of autophagy in les oligodendrocytes}

The timing of the organelle accumulation in les oligodendrocytes coincided with myelin development and loss and may provide insight into a unique cellular mechanism involved in the function of oligodendrocytes. Because of the accumulation of membrane-bound organelles and lysosomes, we investigated whether les oligodendrocytes were undergoing elevated levels of autophagy. During the induction of the autophagic pathway, inclusion membranes are formed and begin to sequester cytoplasmic material. These membranes elongate and enclose to form double-membraned vesicles termed autophagosomes. Once mature, autophagosomes fuse with lysosomes for degradation as autophagolysosomes. To accurately identify each step of the autophagic pathway, we used EM to identify the inclusions in les rats at 2 weeks. Inclusion membranes, autophagosomes, and autophagolysosomes were identified within the cytoplasm of les oligodendrocytes at 2 weeks (Fig. 2A-D). In addition, organelles, including mitochondria, were identified being degraded within lysosomes (Fig. 2D). As autophagy is the only pathway in which organelles are broken down, these findings strongly suggest that autophagy is upregulated within les oligodendrocytes.

To further elucidate the timing of the upregulation of autophagy, a marker for autophagosomes, microtubule-associated protein light chain-3 (LC3) was analyzed by Western blot and immunohistochemistry. During the induction of autophagy, cytoplasmic LC3-I is lipidated and incorporated into the autophagosome membrane as LC3-II (Kabeya et al., 2000; He et al., 2003; Tanida et al., 2004; Wu et al., 2006). Western blot analysis of les and control spinal cord homogenates showed that les samples have a significant increase in LC3-II from 2 weeks until 6 weeks $(p<0.05)$, which coincided with the timing of autophagosome formation within oligodendrocytes (Fig. $3 A, B$ ). To determine whether the increase in LC3-II expression reflected autophagosome formation within les oligodendrocytes, immunohistochemistry for LC3 and PLP was performed. PLP was used as it is the most abundant component of CNS myelin and is expressed within the cytoplasm of les oligodendrocytes. Between 2 and 4 weeks, les oligodendrocytes contained numerous LC3positive punctate bodies characteristic of autophagosomes (Fig. $3 C d-f$, enlarged merge). However, in control oligodendrocytes, LC3 was expressed diffusely throughout the cytoplasm (Fig. $3 \mathrm{Ca}-\mathrm{c}$ ) and did not appear to be incorporated into autophagosomes (Fig. 3, enlarged merge). It was hypothesized that autophagy is upregulated in les to degrade proteins, lipids, and damaged organelles that likely accumulate as a result of the formation and breakdown of unstable myelin. Therefore, an antibody against sequestosome 1 (p62) was used to detect ubiquitinated aggregates targeted for degradation by autophagy (Bjorkoy et al., 2006; Ichimura et al., 2008). p62 was expressed 

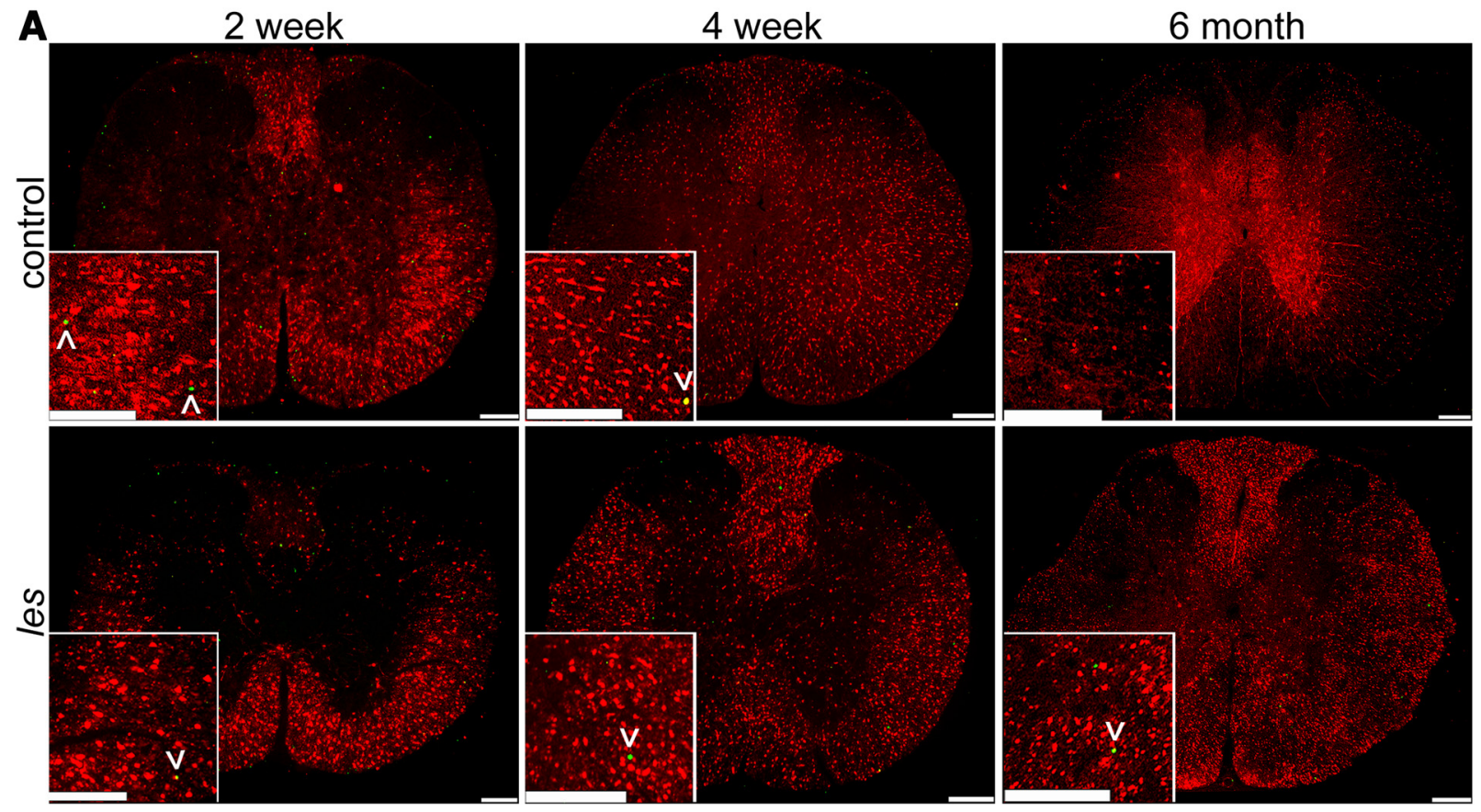

B

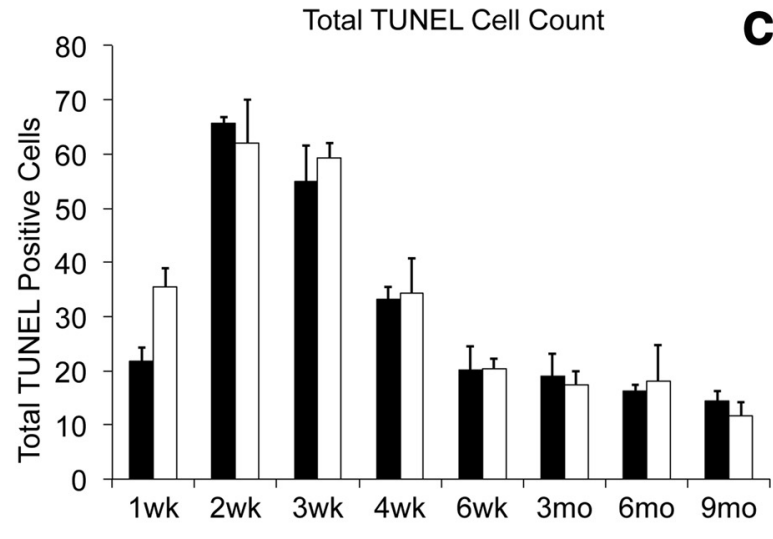

C

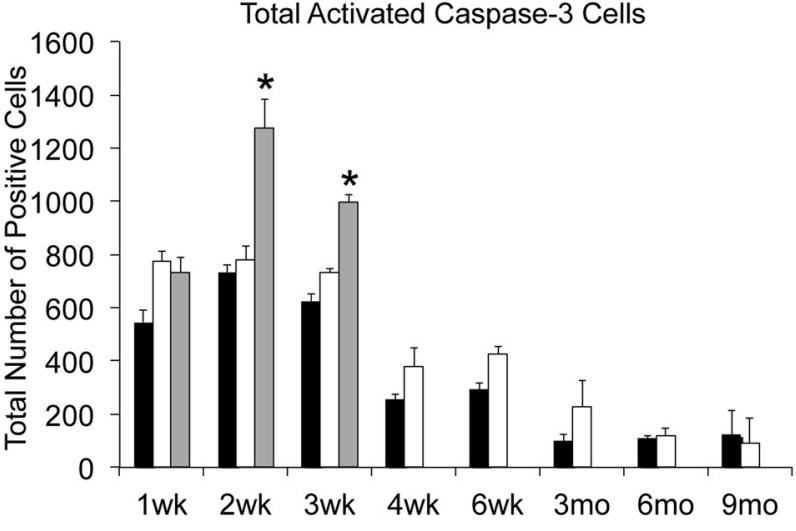
GST-pi

BrdU
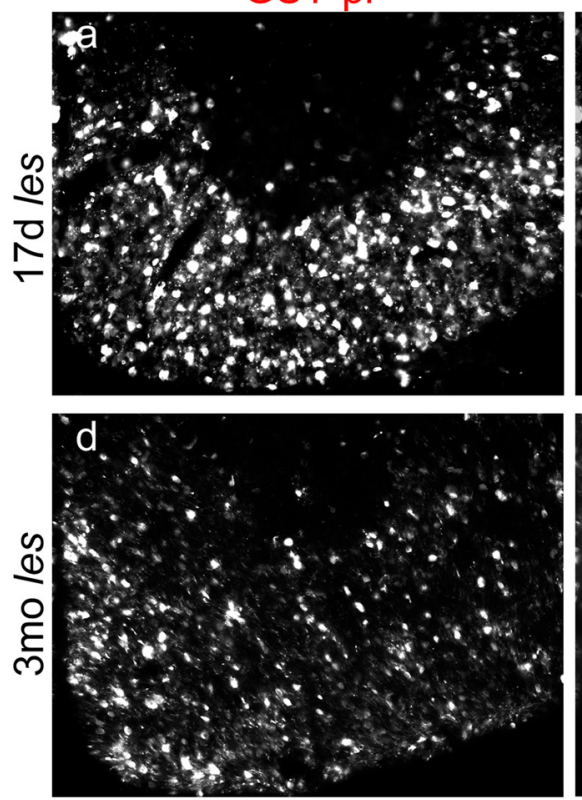
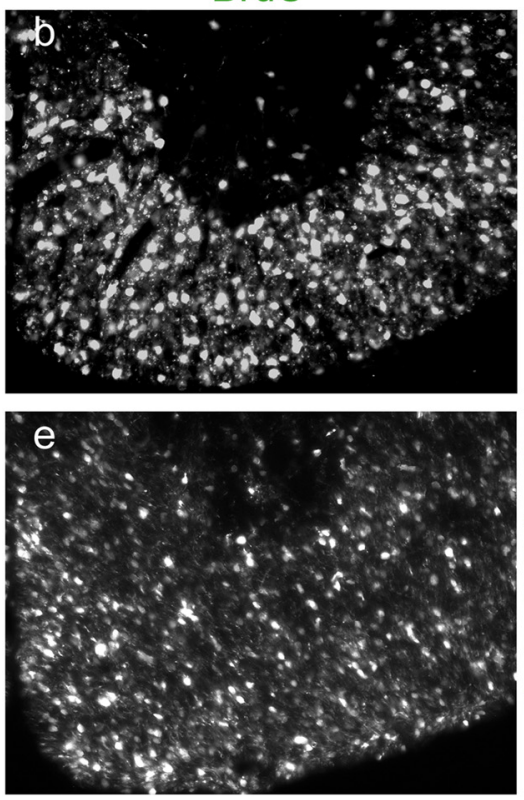

Merge
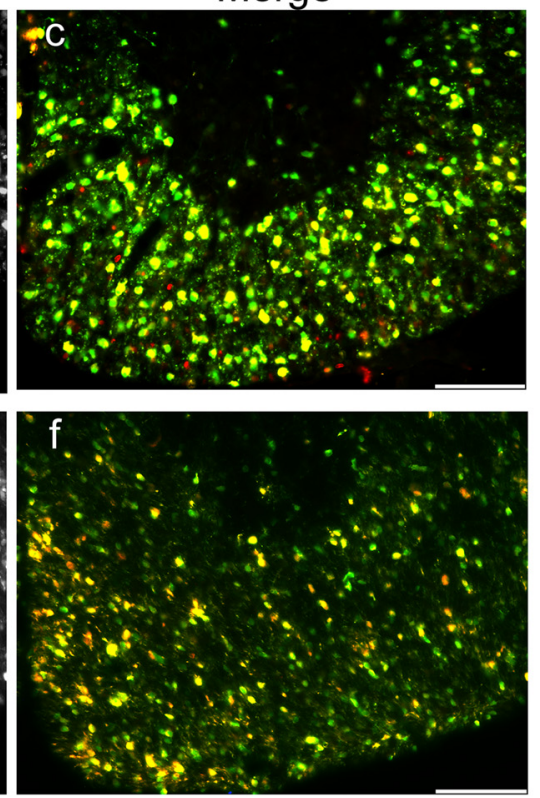

Figure 5. Representative images of TUNEL (green) and GST- $\pi$ immunolabeling (red) in les and control thoracic spinal cord sections at 2 weeks, 4 weeks, and 6 months (A). There is no increase in TUNEL-positive oligodendrocytes ( $\wedge$, magnified inset) in control (top) compared with les spinal cords (bottom) at 2 weeks, 4 weeks, or 6 months. Whole spinal cord images were taken (Figure legend continues.) 

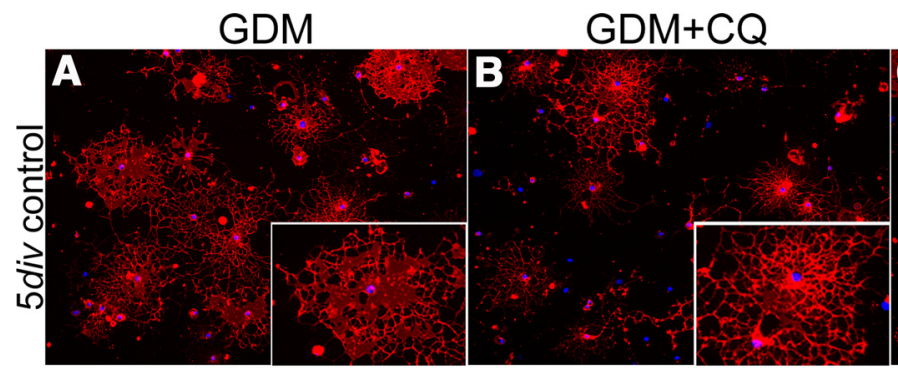

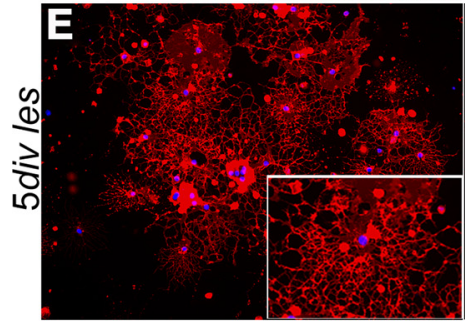

I
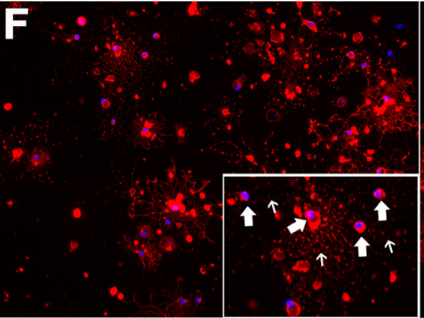

$\mathbf{J}$

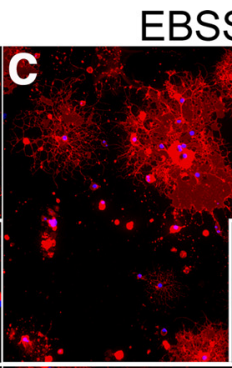

EBSS

$\mathrm{EBSS}+\mathrm{CQ}$

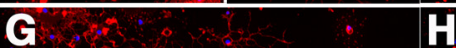

D

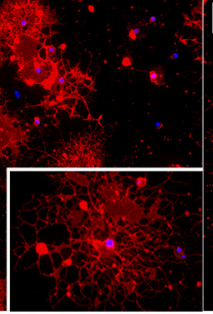

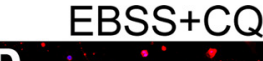
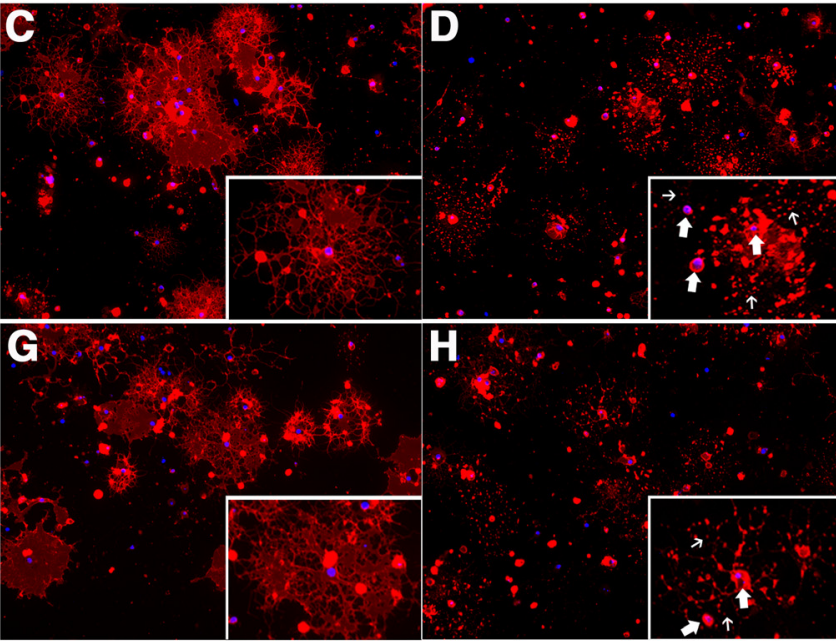

Western Blot Quantification LC3-II
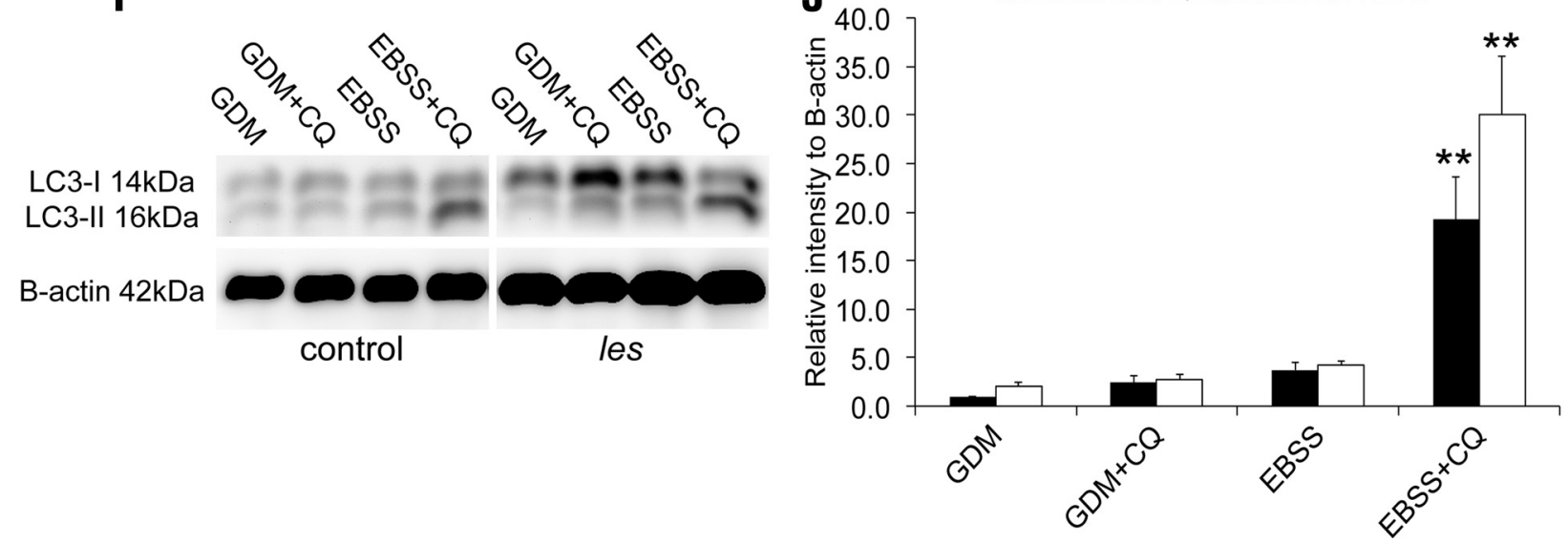

Figure 6. Control $(\boldsymbol{A}-\boldsymbol{D})$ and les $(\boldsymbol{E}-\boldsymbol{H})$ oligodendrocyte progenitor cells were fixed at 5 DIV and labeled with 01 (red) and DAPI (blue). At 3 DIV, the media was replaced with GDM or EBSS with or without CQ. Control and les progenitor cells differentiated into mature oligodendrocytes after incubation in GDM $(\boldsymbol{A}, \boldsymbol{E})$. Control oligodendrocytes were unaffected by the addition of $\mathrm{CQ}(\boldsymbol{B})$; however, les oligodendrocytes exhibited degraded membrane (thin arrows) and nuclear DNA fragmentation (block arrows) followed by incubation in GDM $+C Q(F)$. Interestingly, les oligodendrocytes appeared to have more branching and cytoplasmic extensions after incubation in EBSS alone (G), while there was no obvious difference in the appearance of control oligodendrocytes ( $\boldsymbol{C}$. Both control and les oligodendrocytes exhibit signs of apoptosis after incubation in EBSS $+C Q(\boldsymbol{D}, \boldsymbol{H})$. Western blots performed on protein extracted from both samples confirmed that autophagy was upregulated in les oligodendrocytes $(\boldsymbol{I})$, as there is a significant increase in $\mathrm{LC}$-II after incubation in EBSS $+C Q(J) .{ }^{* *} p<0.001$, GDM versus EBSS $+C Q$ treatments (Student's $t$ test).

highly in the white matter of les between 2 and 4 weeks (Fig. $4 A-C)$ compared with little expression in control white matter (Fig. $4 D-F$ ). In addition, p62 was found to localize within PLPpositive aggregates in les between 2 and 4 weeks (Fig. $4 A, B$, magnified inset). However, by 6 months when myelin development

$\leftarrow$

(Figure legend continued.) with a $4 \times$ objective, and magnified insets were taken with a $20 \times$ objective. Scale bars, $1 \mathrm{~mm}$. Quantification of the total number of TUNEL-positive cells confirmed that there is no increase in oligodendrocyte death in les (white bars) compared with controls (black bars) from 2 weeks until 9 months ( $\boldsymbol{B}$ ). Quantification of activated caspase-3positive cells showed that there was no significant difference in the total number of activated caspase-3-positive cells between les (white bars) and control (black bars) spinal cord sections between 2 weeks until 9 months $(\boldsymbol{C})$. However, there was a significant increase in the number of activated caspase-3-positive cells in the spinal cord of the $m d$ rat (gray bars) from 2 to 3 weeks. ${ }^{*} p<0.05$, $m d$ or les compared with control at the same time point (Student's $t$ test). Representative images of BrdU (green) and GST- $\pi$ (red) double immunolabeling after BrdU injections at $14 \mathrm{~d}$. At $17 \mathrm{~d}, 72 \pm 3 \%$ of GST- $\pi$-positive oligodendrocytes in les also expressed BrdU, showing that oligodendrocytes were successfully labeled early in development (Da-c). At 3 months, $68 \pm 2 \%$ of oligodendrocytes were still present at 3 months (Dd-f). Images are of ventral spinal cord were taken with a $20 \times$ objective. Control oligodendrocytes were also successfully labeled (data not shown). Scale bars, $100 \mu \mathrm{m}$. had ceased, PLP is not expressed as highly within les oligodendrocytes, and there were few p62-positive aggregates within les oligodendrocytes (Fig. 4F).

To determine whether LC3 and p62 were upregulated specifically within les oligodendrocytes, a cell sort for $\mathrm{O}^{+}$oligodendrocytes was performed with les and control spinal cords. Protein extracted from les and control $\mathrm{O}^{+}{ }^{+}$oligodendrocytes showed a significant increase in LC3-II and p62 (Fig. 4G). Moreover, LC3-I expression was significantly reduced in oligodendrocytes within les spinal cord, which indicated that a large proportion of LC3-I may be converted to its lipidated form as LC3-II within the autophagosome membrane (Fig. 4G).

\section{Autophagy does not correlate with oligodendrocyte death}

Myelin development and loss correlated with the upregulation of autophagy in les oligodendrocytes. Although there is an increase in les oligodendrocytes beginning at 3 weeks (Smith et al., 2013), the loss of myelin between 4 and 8 weeks may result from an increase in oligodendrocyte death that could be concealed by the increase in total oligodendrocyte number. Therefore, we exam- 

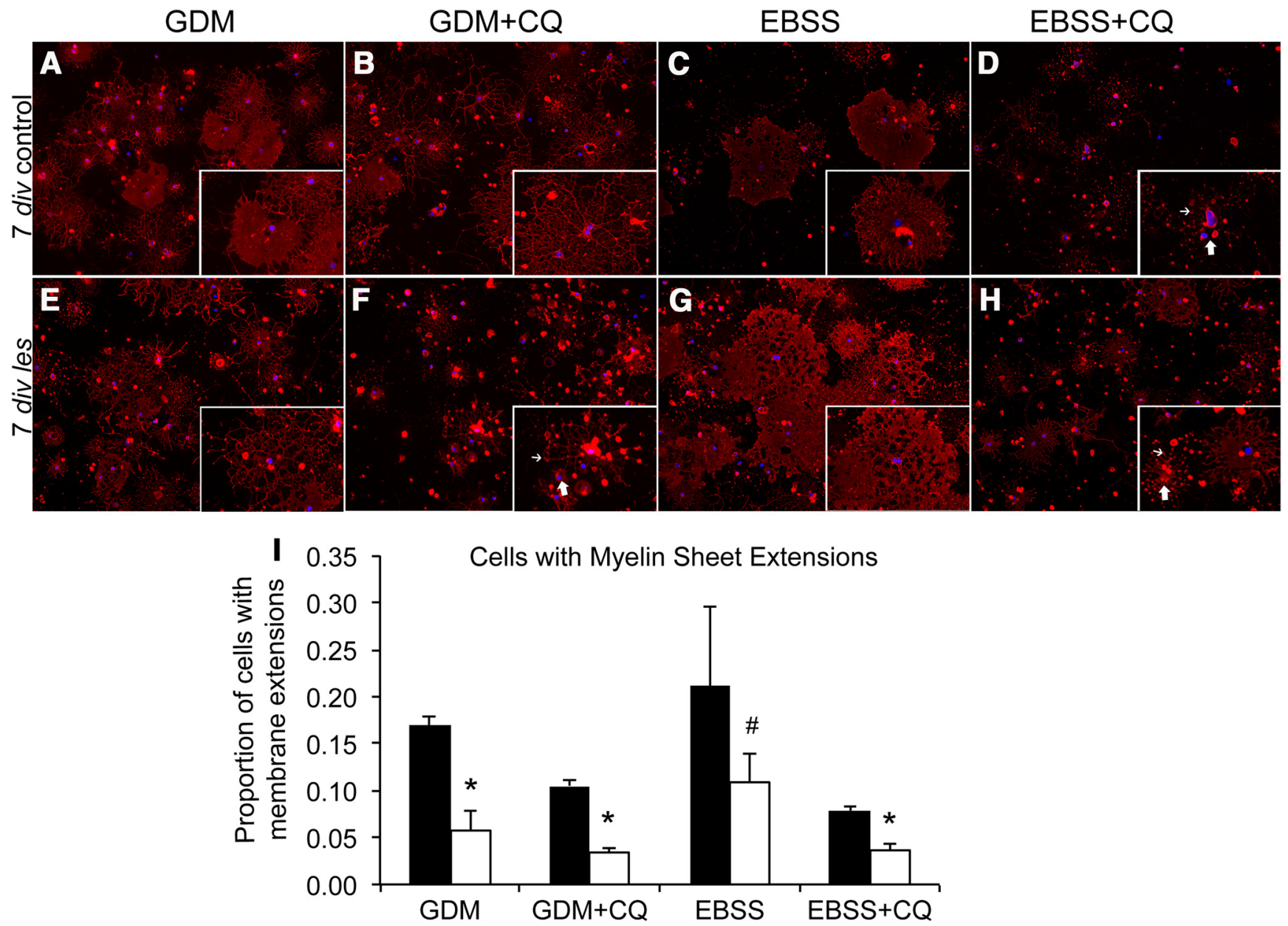

Figure 7. After $48 \mathrm{~h}$ incubation in GDM or EBSS with or without $\mathrm{C} Q$, the cultures were allowed to mature in GDM until 7 DIV. Control and les oligodendrocytes were labeled with 01 (red) and DAPI (blue) $(\boldsymbol{A}-\boldsymbol{H})$, and the number of cells with myelin sheet extensions was quantified at $7 \mathrm{DIV}$ as represented in the graph ( $\boldsymbol{I})$. After incubation in GDM alone, les oligodendrocytes had significantly fewer myelin sheet extensions $(\boldsymbol{E})$ than controls $(\boldsymbol{A})$. However, after incubation in EBSS, les oligodendrocytes produced significantly more myelin sheet extensions $(\boldsymbol{G})$, which was not significantly different from controls $(\boldsymbol{C}$. This increase in membrane extensions could be blocked after incubation in EBSS plus $(\boldsymbol{Q}$, when both control $(\boldsymbol{D})$ and les $(\boldsymbol{H})$ oligodendrocytes began to exhibit signs of apoptosis, such as fragmented membrane (thin arrows) and degraded nuclear DNA (block arrows). ${ }^{*} p<0.05$, control versus les in the same media (Student's $t$ test). ${ }^{*} p<0.05$, les in GDM versus EBSS (Student's $t$ test).

ined whether the transient increase in autophagy correlated with oligodendrocyte death that could account for the myelin loss in les. To determine whether les oligodendrocytes were undergoing cell death that correlated with the timing of autophagy, TUNEL was performed with immunohistochemistry for GST- $\pi$ to quantify the total number of oligodendrocytes undergoing cell death from 1 week until 9 months (Fig. 5A). Quantification of the total number of TUNEL and GST- $\pi$-positive cells, or oligodendrocytes undergoing cell death, in thoracic spinal cord sections demonstrated that les did not have a significant increase in TUNELpositive oligodendrocytes compared with controls from 2 weeks until 9 months (Fig. 5B). To further validate these results, immunolabeling was performed for activated caspase-3. Double immunolabeling for activated caspase- 3 and GST- $\pi$ was not possible because of the sensitivity of the activated caspase- 3 antibody. Therefore, the myelin-deficient $(m d)$ rat was used as a positive control for oligodendrocyte death. The $m d$ rat has a point mutation in PLP that results in the death of oligodendrocytes between 2 and 3 weeks of age (Duncan et al., 1995). It was found that there was no difference between the total number of activated caspase-3-positive cells in les compared with control spinal cord sections from 2 weeks until 9 months (Fig.
$5 C)$. However, there was a significant increase in the number of cells expressing activated caspase- 3 in the $m d$ rat between 2 and 3 weeks (Fig. 5C, gray bars).

As an alternative to cell death, les oligodendrocytes undergoing autophagy may be engulfed via phagocytosis by activated microglia (Zhang et al., 2001). To rule out any alternative possibilities of oligodendrocyte loss, BrdU was used to label oligodendrocyte progenitor cells to determine whether these cells survived throughout the period of upregulated autophagy and became mature oligodendrocytes in adult rats. les and control animals were injected with $50 \mathrm{mg} / \mathrm{kg}$ BrdU every $8 \mathrm{~h}$ beginning at $14 \mathrm{~d}$ of age for $2 \mathrm{~d}$ (six total injections). After BrdU injection, half of the animals were perfused at $17 \mathrm{~d}$ to verify that oligodendrocytes were successfully labeled. Double immunohistochemical labeling showed that the majority of mature oligodendrocytes (72 $\pm 3 \%)$ were successfully labeled with BrdU at $17 \mathrm{~d}$ in les (Fig. $5 \mathrm{Da}-\mathrm{c}$ ) as well as control spinal cord sections $(66 \pm 9 \%)$. At 3 months of age, BrdU-positive oligodendrocytes were still present within control $(59 \pm 3 \%)$ and les spinal cords $(68+2 \%)$ (Fig. 5Dd-f), which demonstrated that les oligodendrocytes had survived through the period of upregulated autophagy. 
A

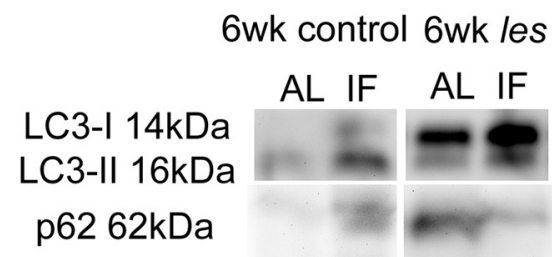

B-actin $42 \mathrm{kDa}$
B
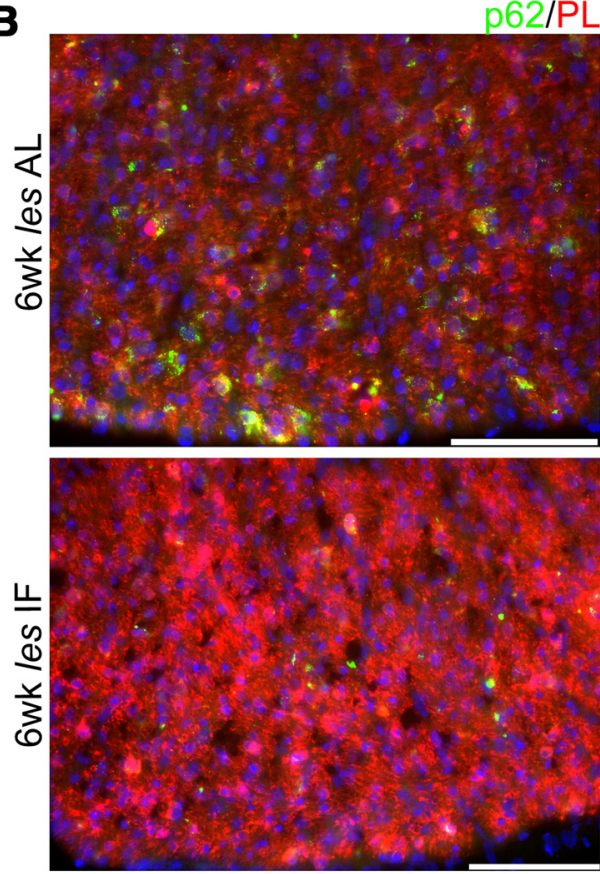

Relative Intensity of LC3-II
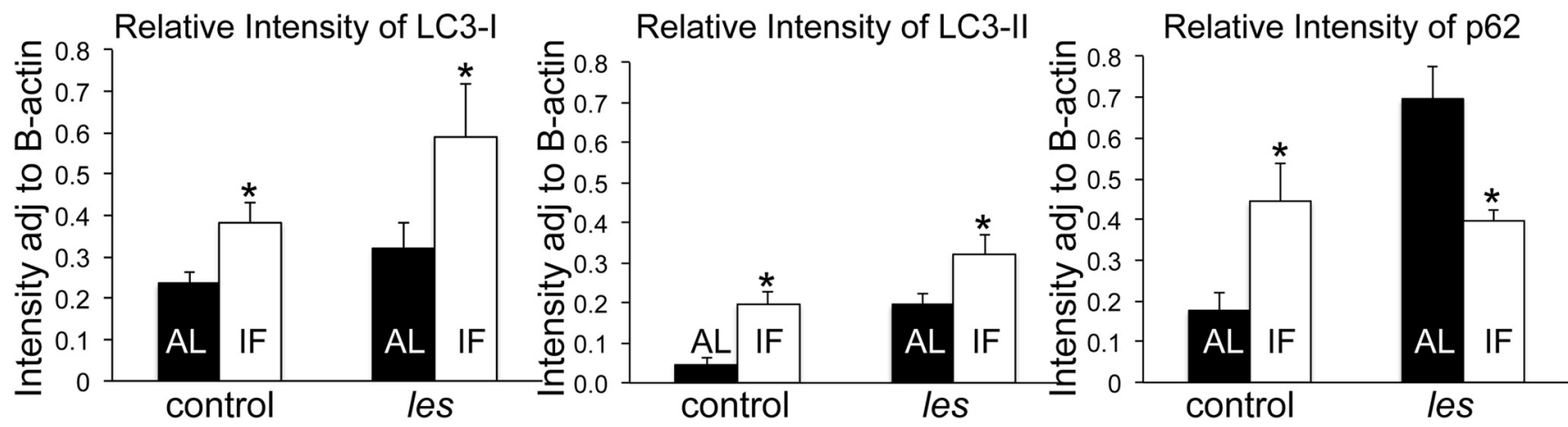

Figure 8. Representative images of Western blot for 6-week-old les and control spinal homogenates after 2 weeks of AL or IF. After IF treatment, there is a significant increase in LC3-I and LC3-II, whereas p62 is significantly decreased after IF $(\boldsymbol{A}){ }^{*} p<0.05$ (Student's $t$ test). $n=4$ for each group. Representative images of ventral spinal cord sections immunolabeled for p62 (green) and PLP (red) $(\boldsymbol{B})$. There is a decrease in p62-positive aggregates within PLP oligodendrocytes in les IF tissue (bottom) compared with les AL (top). Images were taken with a $20 \times$ objective. Scale bars represent $1 \mathrm{~mm}$.

\section{Autophagy promotes survival of les oligodendrocytes in vitro} To investigate the role of autophagy in les, autophagy was manipulated in control and les oligodendrocytes in vitro. Oligospheres from les and control rats were dissociated into single progenitor cells and plated for 3 DIV in GDM (Larsen et al., 2008). At 3 DIV, the media was replaced with either GDM as a control or EBSS to induce autophagy for $48 \mathrm{~h}$ by glucose and serum starvation. CQ was added to the culture medium to block autophagosome breakdown by raising lysosomal pH (Mizushima et al., 2010). Both control and les oligodendrocyte progenitors survived and differentiated into mature, $\mathrm{O}^{+}{ }^{+}$-expressing oligodendrocytes when the media was replaced with fresh GDM (Fig. 6A, B). However, neither control nor les oligodendrocytes survived when autophagosome breakdown was blocked with CQ during incubation in EBSS. These cells exhibited signs of apoptosis with degenerated $\mathrm{O}^{+}{ }^{+}$cytoplasm around fragmented $\mathrm{DAPI}^{+}$nuclear DNA (Fig. $6 D, H$, arrows). Moreover, les oligodendrocytes exhibited similar characteristics of apoptosis when the media was replaced with GDM + CQ (Fig. 6F, arrows), whereas control oligodendrocytes appeared unaffected by the addition of CQ (Fig. 6B). Interestingly, les oligodendrocytes that were incubated for $48 \mathrm{~h}$ in EBSS had an increase in cytoplasmic branching (Fig.
$6 G$, inset). Western blots were performed on protein extracted from control and les oligodendrocytes at 5 DIV to confirm that autophagy was upregulated by incubation in EBSS and that autophagosome breakdown was sufficiently blocked by CQ (Fig. $6 I$ ). These results suggested that an upregulation of autophagy may aid in oligodendrocyte survival in les, as blocking the breakdown of autophagosomes with the addition of CQ resulted in the death of les oligodendrocytes in vitro.

\section{Upregulating autophagy promotes membrane synthesis}

To test whether upregulating autophagy may also enhance myelin sheath formation in les oligodendrocytes, control and les oligodendrocytes were returned to fresh GDM after the initial $48 \mathrm{~h}$ incubation period. After allowing these cells to mature up to 1 week, the number of oligodendrocytes that produced membrane extensions was quantified for each media treatment. At 7 DIV, control oligodendrocytes incubated in GDM had significantly more membrane extensions than les (Fig. $7 \mathrm{~A}, E$ ). However, after EBSS incubation, les oligodendrocytes (Fig. $7 G$ ) produced a significantly greater number of membrane extensions that was similar to control oligodendrocytes (Fig. 7C). However, the increase in membrane extensions after the EBSS incubation could 

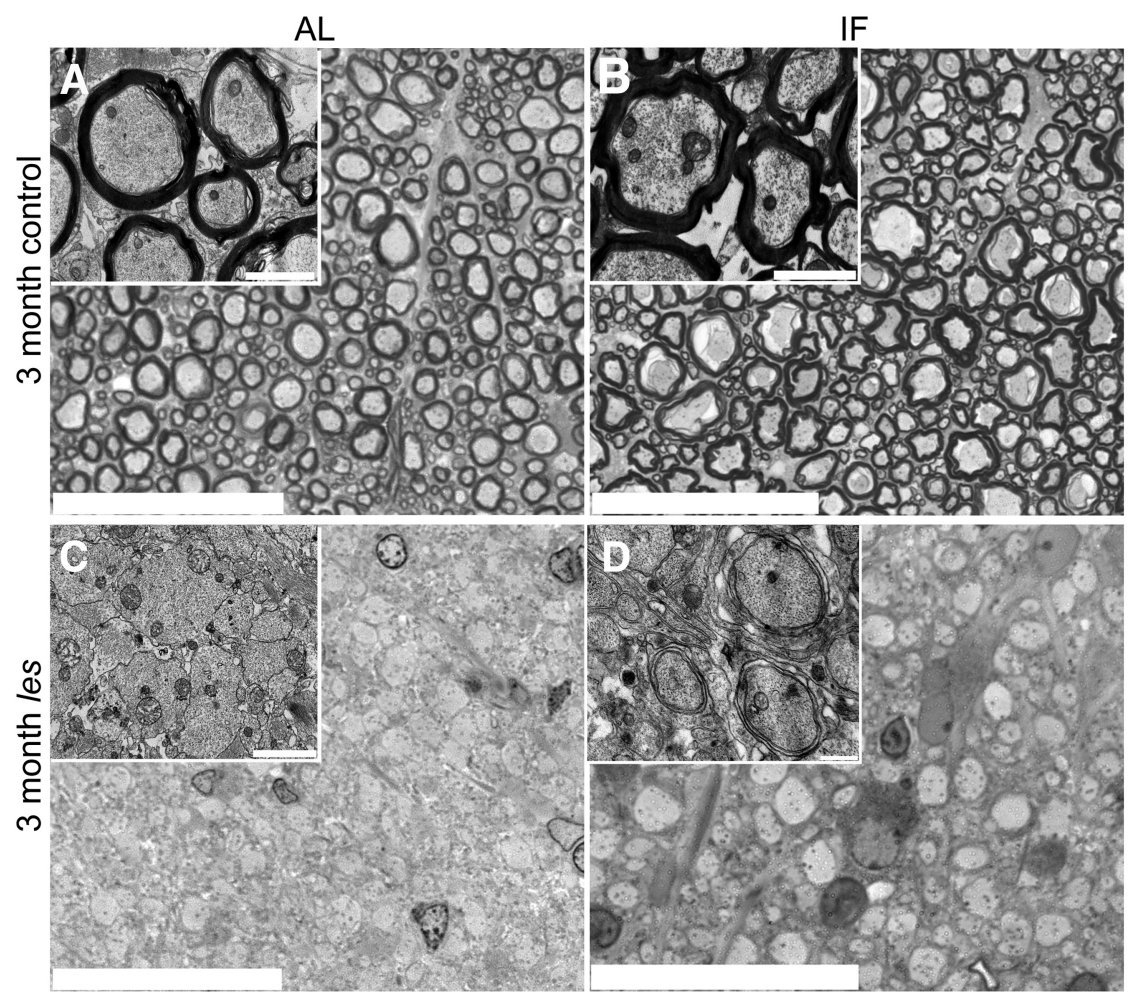

\begin{tabular}{|l|c|c|}
\hline Animal & \% Myelin & G-ratio \\
\hline Control $\mathrm{AL}$ & $61.8+7 \%$ & $.70+.01$ \\
\hline Control IF & $78.1+7 \%^{*}$ & $.59+.02^{*}$ \\
\hline Les AL & $.47+.2 \%$ & $.95+.02$ \\
\hline Les IF & $7.44+2 \%{ }^{*}$ & $.87+.01^{*}$ \\
\hline
\end{tabular}

Figure 9. At 1 month, control and les rats were fed AL or fasted every other day for IF. Representative images of $1 \mu \mathrm{m}$ sections, with electron micrograph insets showing the ventral column of IF or AL control $(A, B)$ and les $(C, D)$. In control spinal cord sections, there appears to be an increase in myelin after IF $(\boldsymbol{A})$ compared with $A L$ diet $(\boldsymbol{B})$. Similarly, in les there are more membrane wrappings around axons after the IF diet (D) compared with $\mathrm{AL}$ (C). Scale bars: inset, $1 \mu \mathrm{m}$; larger image, $1 \mathrm{~mm}$. A quantification of the total proportion of myelinated axons as well as an average g-ratio of myelinated axons from EM images in the table below illustrates that both control and les rats had significantly more myelinated axons and a significantly decreased average g-ratio after IF compared with AL diet. $p<0.05$ (Student's $t$ test). $n=4$ for each group.

be blocked with the addition of CQ (Fig. 7H). Together, these results suggest that autophagy may be a mechanism for promoting membrane development in les oligodendrocytes in vtiro.

\section{Intermittent fasting upregulates autophagy and promotes myelin production}

In vitro experiments illustrated that upregulating autophagy promoted membrane synthesis in les oligodendrocytes. Therefore, we used a previously established protocol of intermittent fasting (Madorsky et al., 2009) to upregulate autophagy in control and les rats in vivo. Upon weaning at 4 weeks, control and les animals were given food every other day for IF or had AL access to food. To determine whether autophagy was successfully upregulated during IF, Western blots were performed on les and control spinal cord protein extracts to measure LC3 and p62 expression 2 weeks after IF or AL diets had begun. After IF, there was an increase in LC3-I and LC3-II in les and control rats (Fig. 8A) and a subsequent decrease in p62 expression in les spinal cord (Fig. $8 A$ ). Immunohistochemistry for $\mathrm{p} 62$ was performed to visualize protein expression in spinal cord tissue. In the les IF group, p62 expression was reduced in PLP-expressing oligodendrocytes compared with les AL sections (Fig. 8B). Consequently, these data suggest that IF upregulates autophagy, which may aid in the breakdown of aggregates within les oligodendrocytes.

After IF or AL treatments for 2 months, the spinal cords of control and les rats were processed to determine whether an upregulation of autophagy had an effect on myelin development. Toluidine blue-stained $1 \mu \mathrm{m}$ sections showed that myelin sheath thickness and the number of myelinated axons appeared to increase in control spinal cord after 2 months IF (Fig. 9B) compared with control rats on the AL diet (Fig. $9 A)$. In addition, les spinal cords appeared to have an increase in the thickness of the membrane that surrounded axons after 2 months IF (Fig. 9D) compared with les on the AL diet (Fig. 9C). EM was used to quantify the total number of myelinated axons and the average myelin thickness in relation to axon diameter (g-ratio). There was a significant increase in the proportion of myelinated axons as well as a decrease in the g-ratio of myelinated axons in control rats after 2 months of IF (Fig. 9B, EM inset) compared with AL (Fig. 9A, EM inset; table). In addition, there was a significant increase in oligodendrocyte membrane wrappings in les spinal cords that engulf axons after IF (Fig. 9D, EM inset) compared with AL (Fig. 9C, EM inset) (Fig. 9 , table). Together, these results suggest that IF can increase myelin development in the spinal cords of les and control rats.

\section{Discussion}

Here, we show, using EM, Western blot, and immunohistochemistry, that autophagy is upregulated in les oligodendrocytes. In addition, p62-positive aggregates are expressed within les oligodendrocytes. An upregulation of autophagy is likely a mechanism for survival during myelin development and loss as les oligodendrocytes survive despite this cellular pathology. In addition, upregulating autophagy both in vitro in les oligodendrocytes and in les and control rats in vivo through IF increased myelin production. Therefore, we have described the timing and induction of autophagy in les and identified a unique cellular mechanism that promotes the survival and function of oligodendrocytes.

\section{Role of MBP in oligodendrocyte autophagy}

Similar accumulations have been reported in the shiverer (shi) mouse and its allele shi mld (Matthieu et al., 1984), which has a large deletion in the MBP gene (Readhead and Hood, 1990). Although autophagy in shi oligodendrocytes has not been previously documented, between 4 and 10 weeks shi oligodendrocytes contain accumulations that resemble lysosomes and vacuolar inclusions (Rosenbluth, 1980; Inoue et al., 1983). Thus, it may be predicted that a mutation in MBP plays a role in the induction of oligodendrocyte autophagy. MBP is not only essential for the compaction of CNS myelin (Roach et al., 
1985; Readhead et al., 1987) but also aids in lipid clustering (Fitzner et al., 2006) and has the capability to bind to myelin and nonmyelin proteins (Harauz et al., 2004). Hence, a mutation in the gene that encodes MBP may perturb the proper transport and clustering of myelin membrane within oligodendrocytes (Harauz et al., 2004; Fitzner et al., 2006; Simons and Trotter, 2007). In addition, the formation of unstable MBP-negative myelin and the subsequent loss of this myelin in both mutants may result in the accumulation of myelin components, including membrane proteins, secretary proteins, and lipids within oligodendrocytes (Fig. $10 B)$. These components are prone to aggregate, which can lead to a further disruption in cellular trafficking that impedes the formation of new and the maintenance of current myelin. Therefore, mutations in MBP may not directly act to induce autophagy, but it is likely that a mutation in MBP is involved indirectly through its role in myelin protein trafficking.

\section{Autophagy promotes survival in les oligodendrocytes}

Autophagy plays a complex role in the health and survival of cells. During cellular stress, including nutrient starvation, hypoxia, and endoplasmic reticulum stress, autophagy is upregulated to aid in cell survival (Klionsky and Emr, 2000; Cuervo, 2004; Ogata et al., 2006). However, autophagy can also play a role in cell death by directly interacting with the apoptosis pathway (Martin and Baehrecke, 2004) or through the degradation of vital cellular components (Maiuri et al., 2007). Here, we determined, through the TUNEL assay along with activated caspase-3 immunolabeling, that there was no increase in cell death in les spinal cord that correlated with the upregulation of autophagy. Furthermore, BrdU labeling confirmed that the majority of les oligodendrocytes survived through the period of enhanced autophagy. Instead of preceding or inducing cell death, autophagy may act to help les oligodendrocytes survive after myelin development and loss. As previously mentioned, the formation and subsequent loss of unstable myelin may result in the accumulation of myelin components within oligodendrocytes. Moreover, perturbed protein trafficking resulting from a lack of MBP may further disturb protein and lipid transport. Hence, autophagy is likely upregulated to aid in the breakdown of these accumulations. Blocking autophagic breakdown in vitro using CQ resulted in les oligodendrocytes undergoing cell death. Therefore, these data suggest that autophagy is upregulated to aid in the survival of oligodendrocytes in les.

\section{Autophagy promotes myelin development}

Upregulating autophagy using EBSS media improved membrane synthesis in les oligodendrocytes in vitro. Autophagy has also

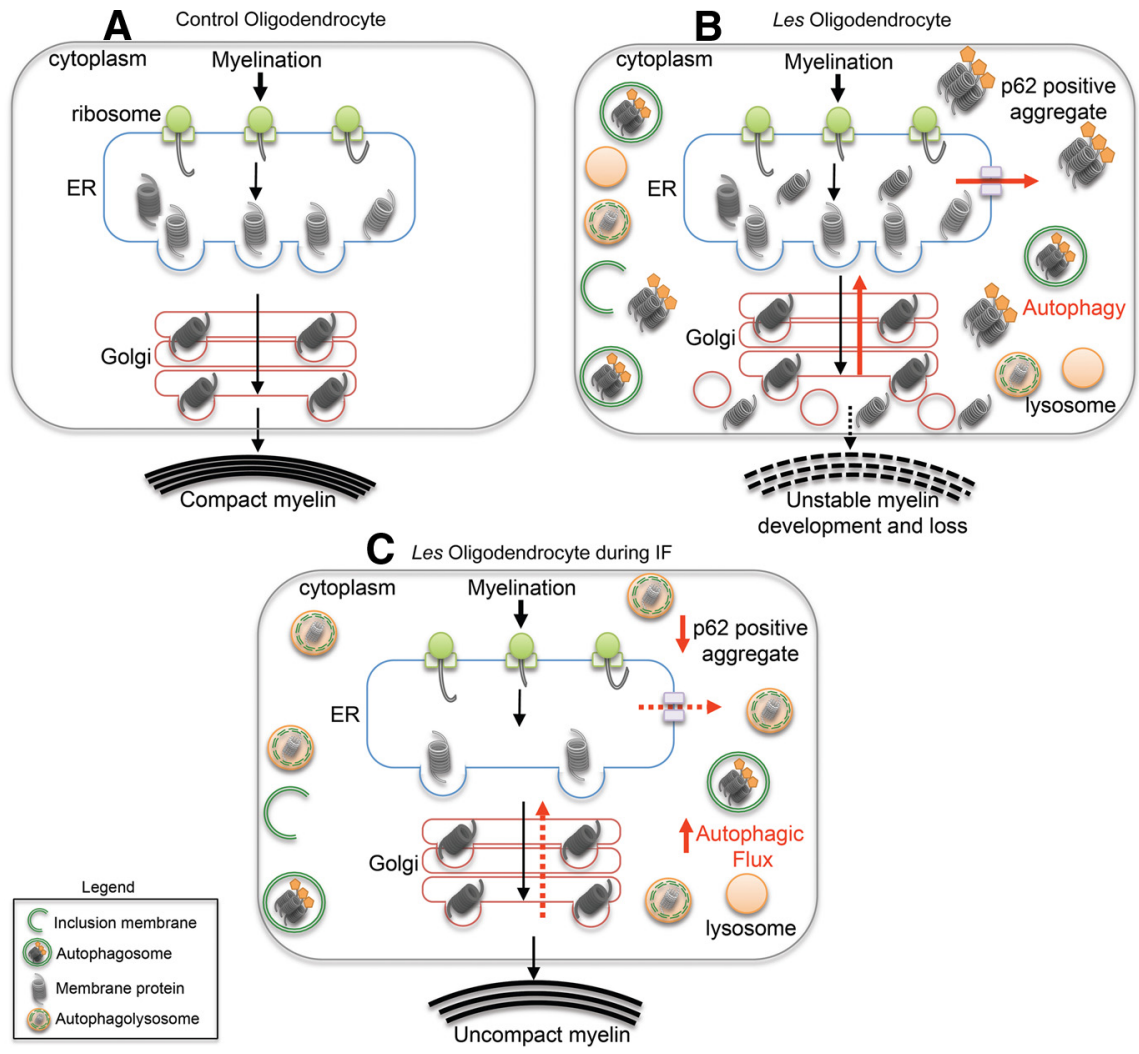

Figure 10. Schematic representation of the role of autophagy in les oligodendrocytes. In control oligodendrocytes, at 2 weeks during peak myelination, membrane proteins, secretory proteins, and myelin proteins are synthesized on ER-bound ribosomes, sy thesized can begin to accumulate within the ER. These proteins can be transported to the cytoplasm and ubiquitinated of p62-positive aggregates and restoration of protein homeostasis $(\boldsymbol{C}$. Therefore, les oligodendrocytes are able to continue protein and lipid synthesis required to maintain and develop new membrane to form uncompact myelin sheaths.

been shown to promote membrane expansion in Schwann cells (Rangaraju and Notterpek, 2011) as well as myelination in explant cultures of dorsal root ganglion that could be blocked by knockdown of ATG12 (Rangaraju et al., 2010). An IF diet in les rats also resulted in an increase in membrane extensions in les spinal cords in vivo. Moreover, IF also increased the number of myelinated axons and myelin sheath thickness in control rats, which is consistent with previous studies in the peripheral nervous system (Madorsky et al., 2009; Rangaraju and Notterpek, 2011). Upregulating autophagy in oligodendrocytes using starvation protocols may be advantageous in multiple aspects. First, dietary restriction, including IF, has been shown to upregulate cellular stress response pathways, including autophagy (Mizushima et al., 2004; Madorsky et al., 2009), which can protect against disease and aging (Martin et al., 2006; Sharma and Kaur, 2007). In addition to upregulating autophagy, IF can reduce cellular oxidative stress and enhance protein chaperones (Martin et al., 2006; Madorsky et al., 2009). Furthermore, during IF, protein synthesis is likely halted or slowed, which can help restore protein homeostasis within les oligodendrocytes. Here, we illustrated that, after IF, there were also fewer p62-positive cytoplasmic aggregates within les oligodendrocytes. Although it was not tested whether autophagy was necessary for the beneficial effects of IF, based on our in vitro findings, we predict that block- 
ing autophagy would only worsen the pathology of les oligodendrocytes. les oligodendrocytes are already undergoing an upregulation of autophagy that may allow them to survive. However, autophagy may not be at high enough levels in les to account for the extensive amount of proteins and lipids being synthesized during this time (Fig. 10B). Thus, further enhancing autophagy via IF may act to help restore function to les oligodendrocytes through the degradation of p62-positive aggregates and the restoration of protein homeostasis (Fig. 10C). It is also worth noting that, although there was an increase in myelin in les rats, there was not an observable difference in the behavioral phenotype of les after IF. Although more myelin membrane was present in les after IF, it was uncompact as it still lacked MBP. Therefore, the lack of behavioral improvement was not surprising. A restoration of MBP would be necessary to fully rescue the phenotype of les rats. However, this study was solely aimed at investigating the role of autophagy in les oligodendrocytes.

\section{Autophagy in myelin disease}

During myelin development, oligodendrocytes must undergo high levels of protein and lipid synthesis, making them particularly sensitive to any disruption during this process (Simons and Trotter, 2007). Therefore, perturbed protein trafficking resulting in the dysfunction and death of myelinating cells has been implicated in various myelin disorders of the peripheral and CNS (D'Antonio et al., 2009; Lin and Popko, 2009). For example, in Charcot-Marie-Tooth disease, the overexpression of and/or mutations in the gene that encodes peripheral myelin protein 22 (PMP22) results in cytoplasmic accumulations that inhibit protein degradation pathways (Notterpek et al., 1999; Ryan et al., 2002; Fortun et al., 2006). It was shown that IF can decrease PMP22 aggregates and alleviate the neuropathic phenotype in a model of Charcot-Marie-Tooth disease through the enhancement of protein chaperones and the upregulation of autophagy (Madorsky et al., 2009). Here, we have shown that intermittent fasting can upregulate autophagy in oligodendrocytes and increase myelination in les as well as control CNS. Interestingly, disruptions in oligodendrocyte protein homeostasis have been described in several CNS myelin disorders, including vanishing white matter disease (van der Voorn et al., 2005; van Kollenburg et al., 2006), multiple sclerosis (Getts et al., 2008), and PelizeausMerzbacher disease (Dhaunchak and Nave, 2007). Moreover, autophagy can be easily enhanced through diet or pharmacologically with drugs, such as rapamycin (Menzies and Rubinsztein, 2010). Therefore, further investigation of this pathway may lead to novel therapies that aid in the survival and function of myelinating cells in certain myelin diseases.

\section{References}

Avellana-Adalid V, Nait-Oumesmar B, Lachapelle F, Baron-Van Evercooren A (1996) Expansion of rat oligodendrocyte progenitors into proliferative "oligospheres" that retain differentiation potential. J Neurosci Res 45:558-570. CrossRef Medline

Bjartmar C, Yin X, Trapp BD (1999) Axonal pathology in myelin disorders. J Neurocytol 28:383-395. CrossRef Medline

Bjørkoy G, Lamark T, Johansen T (2006) p62/SQSTM1: a missing link between protein aggregates and the autophagy machinery. Autophagy 2:138-139. CrossRef Medline

Campagnoni AT, Skoff RP (2001) The pathobiology of myelin mutants reveal novel biological functions of the MBP and PLP genes. Brain Pathol 11:74-91. Medline

Cuervo AM (2004) Autophagy: in sickness and in health. Trends Cell Biol 14:70-77. CrossRef Medline

D’Antonio M, Feltri ML, Wrabetz L (2009) Myelin under stress. J Neurosci Res 87:3241-3249. CrossRef Medline
Delaney KH, Kwiecien JM, Wegiel J, Wisniewski HM, Percy DH, Fletch AL (1995) Familial dysmyelination in a Long-Evans rat mutant. Lab Anim Sci 45:547-553. Medline

Dhaunchak AS, Nave KA (2007) A common mechanism of PLP/DM20 misfolding causes cysteine-mediated endoplasmic reticulum retention in oligodendrocytes and Pelizaeus-Merzbacher disease. Proc Natl Acad Sci U S A 104:17813-17818. CrossRef Medline

Duncan ID, Nadon NL, Hoffman RL, Lunn KF, Csiza C, Wells MR (1995) Oligodendrocyte survival and function in the long-lived strain of the myelin deficient rat. J Neurocytol 24:745-762. CrossRef Medline

Fitzner D, Schneider A, Kippert A, Möbius W, Willig KI, Hell SW, Bunt G, Gaus K, Simons M (2006) Myelin basic protein-dependent plasma membrane reorganization in the formation of myelin. EMBO J 25:50375048. CrossRef Medline

Fortun J, Go JC, Li J, Amici SA, Dunn WA Jr, Notterpek L (2006) Alterations in degradative pathways and protein aggregation in a neuropathy model based on PMP22 overexpression. Neurobiol Dis 22:153-164. CrossRef Medline

Getts MT, Getts DR, Kohm AP, Miller SD (2008) Endoplasmic reticulum stress response as a potential therapeutic target in multiple sclerosis. Therapy 5:631-640. CrossRef Medline

Griffiths I, Klugmann M, Anderson T, Yool D, Thomson C, Schwab MH, Schneider A, Zimmermann F, McCulloch M, Nadon N, Nave KA (1998) Axonal swellings and degeneration in mice lacking the major proteolipid of myelin. Science 280:1610-1613. CrossRef Medline

Harauz G, Ishiyama N, Hill CM, Bates IR, Libich DS, Farès C (2004) Myelin basic protein: diverse conformational states of an intrinsically unstructured protein and its roles in myelin assembly and multiple sclerosis. Micron 35:503-542. CrossRef Medline

He H, Dang Y, Dai F, Guo Z, Wu J, She X, Pei Y, Chen Y, Ling W, Wu C, Zhao S, Liu JO, Yu L (2003) Post-translational modifications of three members of the human MAP1LC3 family and detection of a novel type of modification for MAP1LC3B. J Biol Chem 278:29278-29287. CrossRef Medline

Ichimura Y, Kominami E, Tanaka K, Komatsu M (2008) Selective turnover of p62/A170/SQSTM1 by autophagy. Autophagy 4:1063-1066. Medline

Inoue Y, Inoue K, Terashima T, Mikoshiba K, Tsukada Y (1983) Developmental changes of oligodendroglia in the posterior funiculus of "Shiverer" mutant mouse spinal cord, with special reference to myelin formation. Anat Embryol (Berl) 168:159-171. CrossRef Medline

Kabeya Y, Mizushima N, Ueno T, Yamamoto A, Kirisako T, Noda T, Kominami E, Ohsumi Y, Yoshimori T (2000) LC3, a mammalian homologue of yeast Apg8p, is localized in autophagosome membranes after processing. EMBO J 19:5720-5728. CrossRef Medline

Klionsky DJ, Emr SD (2000) Autophagy as a regulated pathway of cellular degradation. Science 290:1717-1721. CrossRef Medline

Kwiecien JM, O'Connor LT, Goetz BD, Delaney KH, Fletch AL, Duncan ID (1998) Morphological and morphometric studies of the dysmyelinating mutant, the Long-Evans shaker rat. J Neurocytol 27:581-591. CrossRef Medline

Larsen EC, Kondo Y, Fahrenholtz CD, Duncan ID (2008) Generation of cultured oligodendrocyte progenitor cells from rat neonatal brains. Curr Protoc Stem Cell Biol Chapter 2:Unit 2D1-13. CrossRef Medline

Lin W, Popko B (2009) Endoplasmic reticulum stress in disorders of myelinating cells. Nat Neurosci 12:379-385. CrossRef Medline

Madorsky I, Opalach K, Waber A, Verrier JD, Solmo C, Foster T, Dunn WA Jr, Notterpek L (2009) Intermittent fasting alleviates the neuropathic phenotype in a mouse model of Charcot-Marie-Tooth disease. Neurobiol Dis 34:146-154. CrossRef Medline

Maiuri MC, Zalckvar E, Kimchi A, Kroemer G (2007) Self-eating and selfkilling: crosstalk between autophagy and apoptosis. Nat Rev Mol Cell Biol 8:741-752. CrossRef Medline

Martin B, Mattson MP, Maudsley S (2006) Caloric restriction and intermittent fasting: two potential diets for successful brain aging. Ageing Res Rev 5:332-353. CrossRef Medline

Martin DN, Baehrecke EH (2004) Caspases function in autophagic programmed cell death in Drosophila. Development 131:275-284. CrossRef Medline

Matthieu JM, Omlin FX, Ginalski-Winkelmann H, Cooper BJ (1984) Myelination in the CNS of mld mutant mice: comparison between composition and structure. Brain Res 315:149-158. Medline 
Menzies FM, Rubinsztein DC (2010) Broadening the therapeutic scope for rapamycin treatment. Autophagy 6:286-287. CrossRef Medline

Mizushima N, Yamamoto A, Matsui M, Yoshimori T, Ohsumi Y (2004) In vivo analysis of autophagy in response to nutrient starvation using transgenic mice expressing a fluorescent autophagosome marker. Mol Biol Cell 15:1101-1111. CrossRef Medline

Mizushima N, Yoshimori T, Levine B (2010) Methods in mammalian autophagy research. Cell 140:313-326. CrossRef Medline

Nave KA, Trapp BD (2008) Axon-glial signaling and the glial support of axon function. Annu Rev Neurosci 31:535-561. CrossRef Medline

Notterpek L, Ryan MC, Tobler AR, Shooter EM (1999) PMP22 accumulation in aggresomes: implications for CMT1A pathology. Neurobiol Dis 6:450-460. CrossRef Medline

O'Connor LT, Goetz BD, Kwiecien JM, Delaney KH, Fletch AL, Duncan ID (1999) Insertion of a retrotransposon in Mbp disrupts mRNA splicing and myelination in a new mutant rat. J Neurosci 19:3404-3413. Medline

Ogata M, Hino S, Saito A, Morikawa K, Kondo S, Kanemoto S, Murakami T, Taniguchi M, Tanii I, Yoshinaga K, Shiosaka S, Hammarback JA, Urano F, Imaizumi K (2006) Autophagy is activated for cell survival after endoplasmic reticulum stress. Mol Cell Biol 26:9220-9231. CrossRef Medline

Rangaraju S, Verrier JD, Madorsky I, Nicks J, Dunn WA Jr, Notterpek L (2010) Rapamycin activates autophagy and improves myelination in explant cultures from neuropathic mice. J Neurosci 30:11388-11397. CrossRef Medline

Rangaraju S, Notterpek L (2011) Autophagy aids membrane expansion by neuropathic Schwann cells. Autophagy 7:238-239. CrossRef Medline

Readhead C, Hood L (1990) The dysmyelinating mouse mutations shiverer (shi) and myelin deficient (shimld). Behav Genet 20:213-234. CrossRef Medline

Readhead C, Popko B, Takahashi N, Shine HD, Saavedra RA, Sidman RL, Hood L (1987) Expression of a myelin basic protein gene in transgenic shiverer mice: correction of the dysmyelinating phenotype. Cell 48:703-712. CrossRef Medline

Roach A, Takahashi N, Pravtcheva D, Ruddle F, Hood L (1985) Chromosomal mapping of mouse myelin basic protein gene and structure and transcription of the partially deleted gene in shiverer mutant mice. Cell 42:149-155. CrossRef Medline

Rosenbluth J (1980) Central myelin in the mouse mutant shiverer. J Comp Neurol 194:639-648. CrossRef Medline

Ryan MC, Shooter EM, Notterpek L (2002) Aggresome formation in neu- ropathy models based on peripheral myelin protein 22 mutations. Neurobiol Dis 10:109-118. CrossRef Medline

Scherer S (1999) Axonal pathology in demyelinating diseases. Ann Neurol 45:6-7. CrossRef Medline

Sharma S, Kaur G (2007) Intermittent dietary restriction as a practical intervention in aging. Ann N Y Acad Sci 1114:419-427. CrossRef Medline

Simons M, Trotter J (2007) Wrapping it up: the cell biology of myelination. Curr Opin Neurobiol 17:533-540. CrossRef Medline

Smith CM, Cooksey E, Duncan ID (2013) Myelin loss does not lead to axonal degeneration in a long-lived model of chronic demyelination. J Neurosci 33:2718-2727. CrossRef Medline

Soldán MM, Pirko I (2012) Biogenesis and significance of central nervous system myelin. Semin Neurol 32:9-14. CrossRef Medline

Tanida I, Ueno T, Kominami E (2004) Human light chain 3/MAP1LC3B is cleaved at its carboxyl-terminal Met121 to expose Gly120 for lipidation and targeting to autophagosomal membranes. J Biol Chem 279: 47704-47710. CrossRef Medline

van der Voorn JP, van Kollenburg B, Bertrand G, Van Haren K, Scheper GC, Powers JM, van der Knaap MS (2005) The unfolded protein response in vanishing white matter disease. J Neuropathol Exp Neurol 64:770-775. CrossRef Medline

van Kollenburg B, van Dijk J, Garbern J, Thomas AA, Scheper GC, Powers JM, van der Knaap MS (2006) Glia-specific activation of all pathways of the unfolded protein response in vanishing white matter disease. J Neuropathol Exp Neurol 65:707-715. CrossRef Medline

Wu J, Dang Y, Su W, Liu C, Ma H, Shan Y, Pei Y, Wan B, Guo J, Yu L (2006) Molecular cloning and characterization of rat LC3A and LC3B: two novel markers of autophagosome. Biochem Biophys Res Commun 339:437-442. CrossRef Medline

Yin X, Baek RC, Kirschner DA, Peterson A, Fujii Y, Nave KA, Macklin WB, Trapp BD (2006) Evolution of a neuroprotective function of central nervous system myelin. J Cell Biol 172:469-478. CrossRef Medline

Ylä-Anttila P, Vihinen H, Jokitalo E, Eskelinen EL (2009) Monitoring autophagy by electron microscopy in mammalian cells. Methods Enzymol 452:143-164. CrossRef Medline

Zhang SC, Lundberg C, Lipsitz D, O’Connor LT, Duncan ID (1998) Generation of oligodendroglial progenitors from neural stem cells. J Neurocytol 27:475-489. CrossRef Medline

Zhang SC, Goetz BD, Carré JL, Duncan ID (2001) Reactive microglia in dysmyelination and demyelination. Glia 34:101-109. CrossRef Medline 